\title{
Testing a new automated single ring infiltrometer for Beerkan infiltration experiments
}

\author{
Simone Di Prima (1), Laurent Lassabatère (2), Rafael Angulo-Jaramillo (2), Vincenzo Bagarello (1), and \\ Massimo Iovino (1) \\ (1) Dipartimento di Scienze Agrarie e Forestali, Università degli Studi di Palermo, Italy (simone.diprima@unipa.it), (2) \\ Laboratoire des Sciences de l'Environnement (LSE), ENTPE, Université de Lyon, Vaulx-en-Velin, France
}

The Beerkan method along with BEST algorithms is an alternative technique to conventional laboratory or field measurements for rapid and low-cost estimation of soil hydraulic properties. The Beerkan method is simple to conduct but requires an operator to pour known volumes of water through the ring and can be time-consuming. To alleviate this need, a new cheap infiltrometer equipped with a data acquisition system, allowing automation of Beerkan infiltration experiments, was recently designed and is presented in a companion paper. Yet, it has never been tested against a wide range of experimental conditions (soils, initial water saturation, etc.). In this paper, we tested the automated infiltrometer with the aim to validate its applicability to the Beerkan infiltration experiment under several experimental circumstances. In addition, we assessed the accuracy of BEST methods on the data obtained with the infiltrometer for the estimation of saturated soil hydraulic conductivity and sorptivity. For this purpose, we used both analytically generated and real experimental data. The analytically generated data simulate infiltration experiments carried out with the infiltrometer on five contrasting soils from UNSODA database and different initial water contents. The total volume of water to be infiltrated and the volume increments are fixed by the infiltrometer characteristics. Then, inverse analysis of the analytically generated data was performed using the three available BEST algorithms to derive saturated soil hydraulic conductivity and sorptivity that were compared to the reference values. The results of the analytical assessment showed that the infiltrometer along with BEST methods could lead to accurate estimates in most cases thus validating the design of the studied infiltrometer and its combination with BEST algorithms. Some soils (mostly loam) and some hydric conditions (high initial water contents) may lead to misestimate soil properties or failure of BEST algorithms according to numerical results. In these cases, the failures are due to the fact that steady state is not properly reached or the transient state is not properly described (not enough points in the transient state). Finally, the infiltrometer was tested in different soil types. All experiments were carried in an infiltration basin located in the pumping well filed of Crépieux-Charmy, which provides drinking water for the Lyon metropolitan area. Water infiltration experiments were conducted on the subsoil, the layer of sand embedded at surface, either clean or clogged. Experiments and analysis with BEST algorithms proved efficient to pinpoint the decrease in hydraulic conductivity due to clogging. The experiments showed that the automatic data collection increases measurement speeds and allows for more efficient data handling and analysis. 